\title{
الترادف عند الرحالة حتى نهاية القرن الثامن الهجري
}

\section{أ.د حسن جعفر صادق}

جامعة بغداد/ كلية التربية ابن رشد للعلوم

الإنسانية/قسم اللغة العربية
الباحثة بسمة عبد الله فاضل جامعة بغداد/ كلية التربية ابن رشد للعلوم الإنسانية/قسم اللغة العربية

\section{k.klam90@yahoo.com}

(مُلَخََّصُ البَحثث)

يعـد التـرادف مظهـرًا مـن مظـاهر اللغـة العربيـة، وخاصـية مهمــة مـن خصائصـهـا،

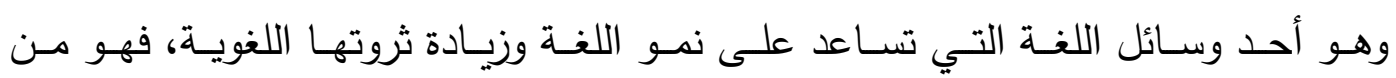
الوسـائل التـي أغنـت المعجمـات العربيـة بالعديـد مـن الألفـاظ حتـى أصـبحت المعجمـات

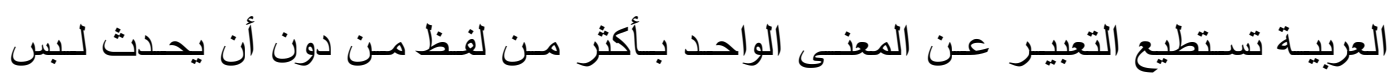
فـي المعنـى، وبواسـطة التـرادف نسـتطيع معرفـة الألفـاظ المشـتركة مــع بعضـهـا دلاليًا،

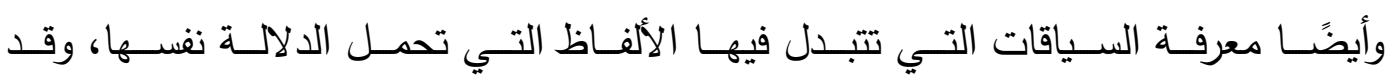
تميـزت كتـب الرحالـة بوجــد عـدد مـن الألفـاظ المترادفـة؛ لأنهـم درسـوا لغــات البــــان

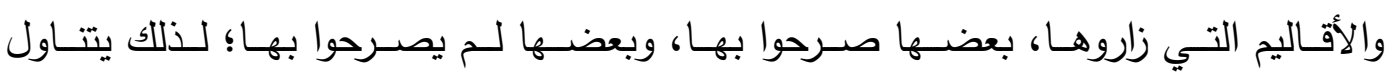

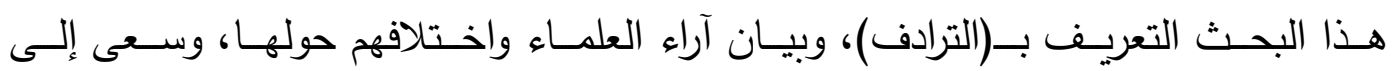
استقراء الألفاظ المترادفة في كتب الرحالة، ووصفها وموازنتها بما قاله اللغويون.

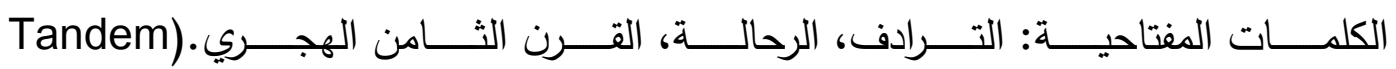
(Nomads. 8th century AH المقدمة:

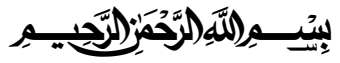

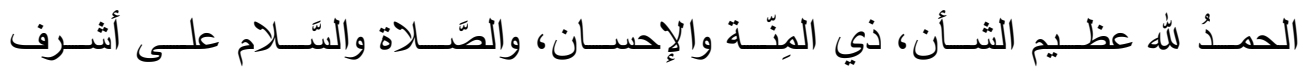

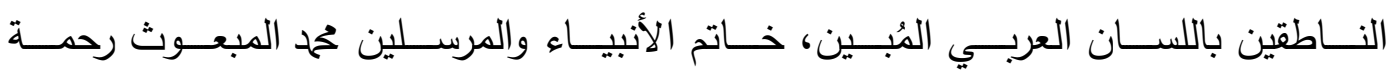
للعالمين، وعلى آله الطيبين الطاهرين.

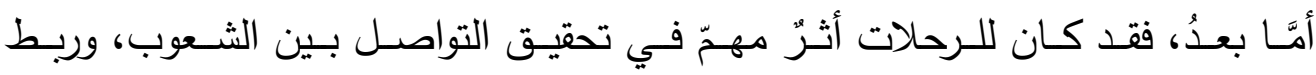

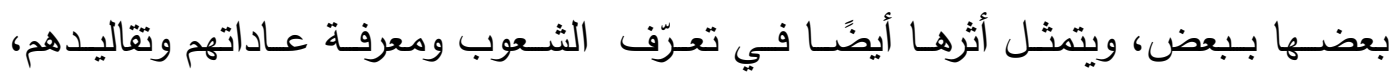

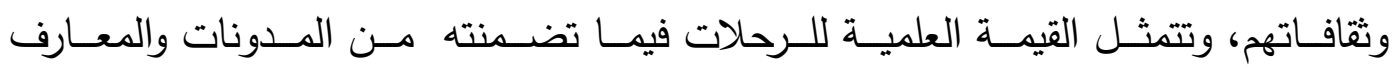

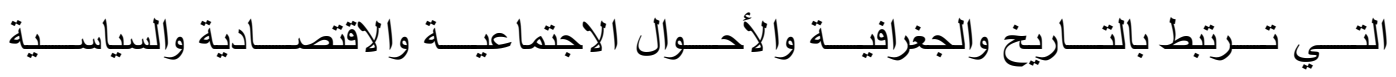

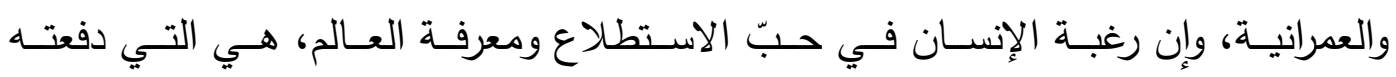

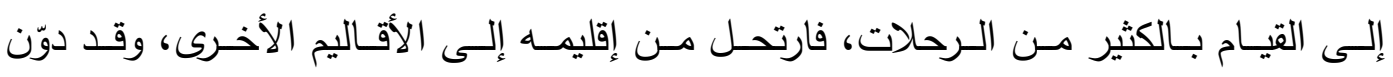




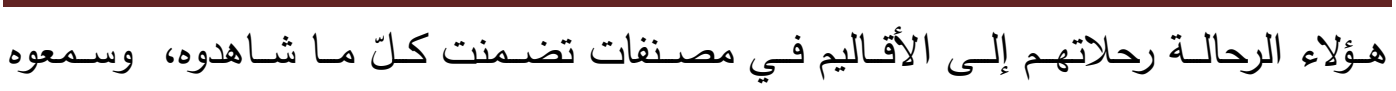
في الأقاليم التي زاروها.

لـذلك تضــنت كتب الرحالـة الكثيـر مـن الألفـاظ المترادفـة، فـالترادف مـن الأسـس

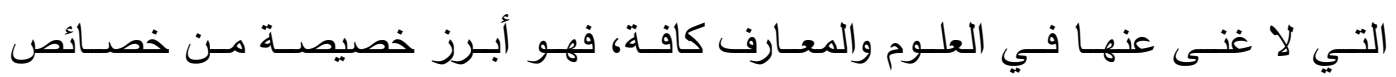

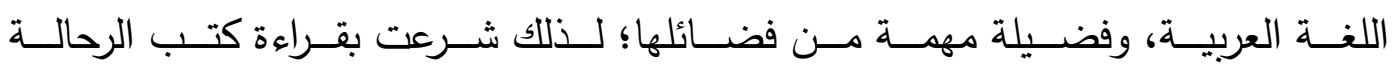

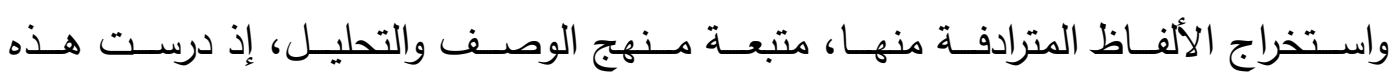
الألفاظ ووصفتها وصفًا دقيقًا، وموازنتها بما قاله اللغويون.

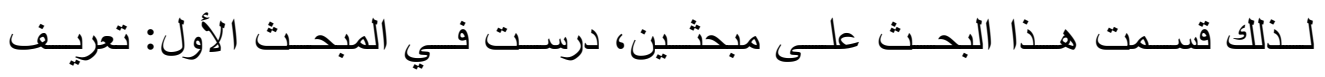

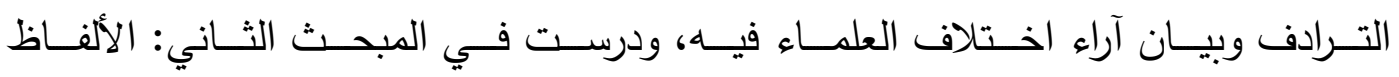
المترادفة الواردة عند الرحالة وقد قسمتها على قسمين.

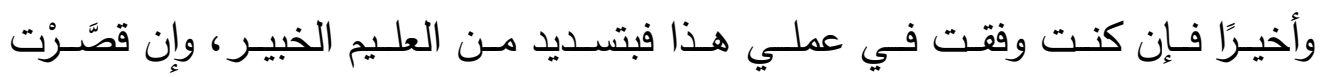
فمن نفسي، والحمدلله دائمًا وأبدًا.

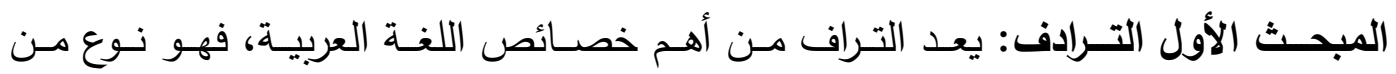

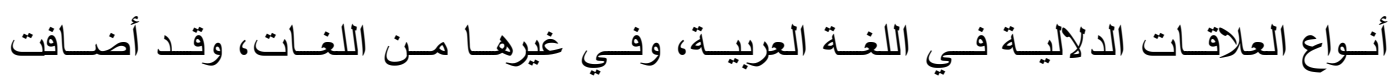

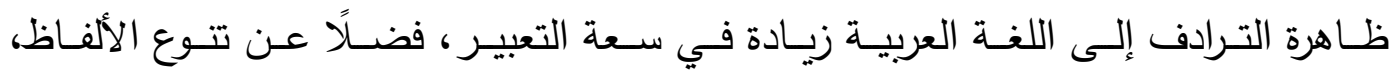

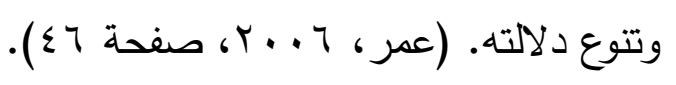

وقد حظيت ظـاهرة الترادف باهتمـام عدد كبير مـن اللغويين قديمًا وحديثًا، ومـنهم

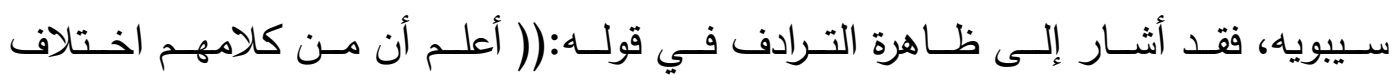

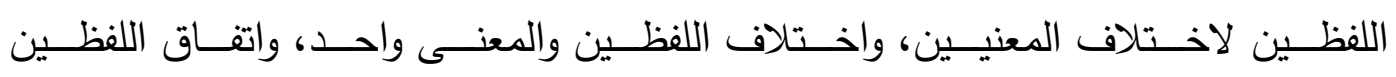

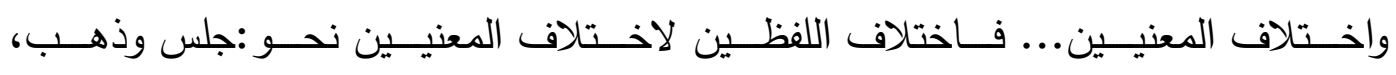

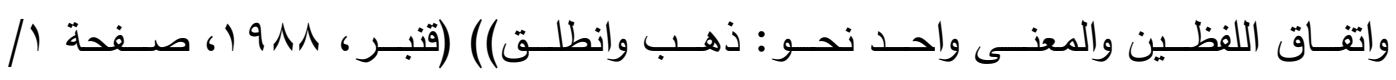

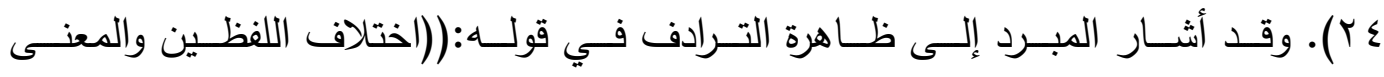

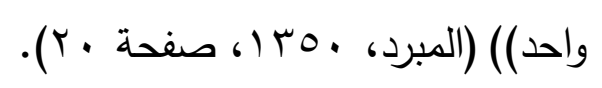

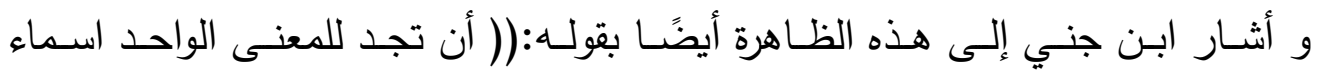

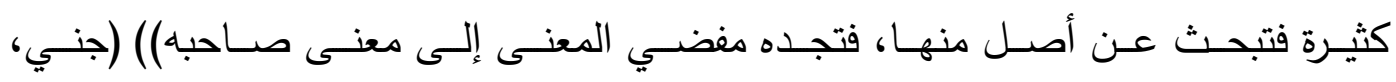

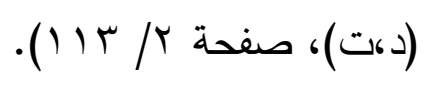

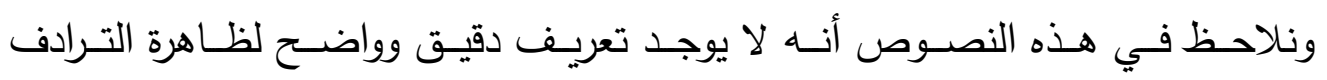

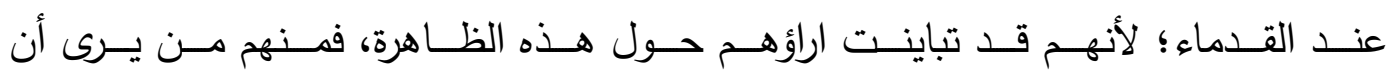

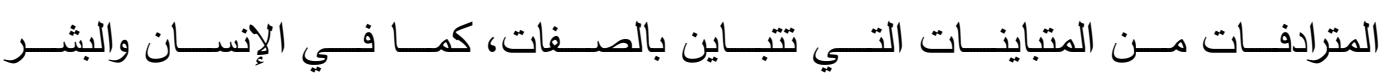

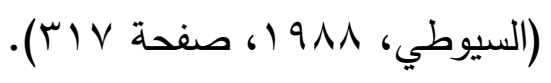


وكـان أوّل مـن أنكـر التـرادف واتبعـهـ عـدد مـن العلمـاء، (ابـن الأعرابـي)، إذ قـال:

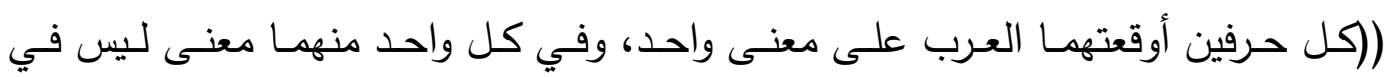

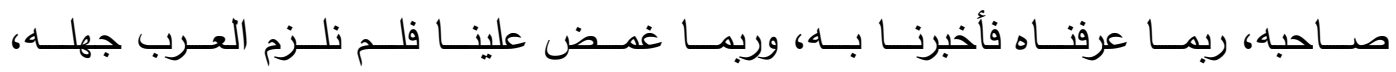

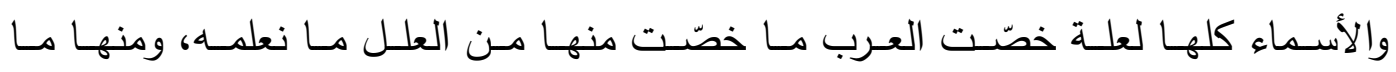

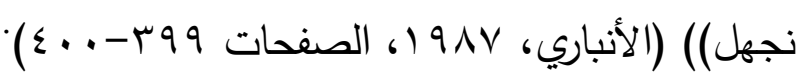

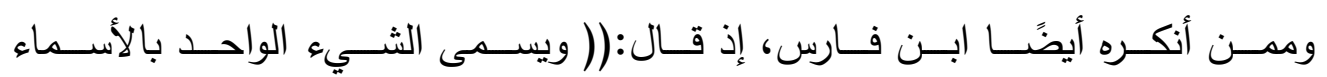

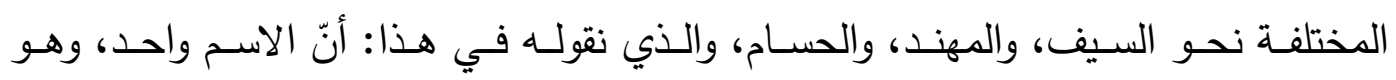

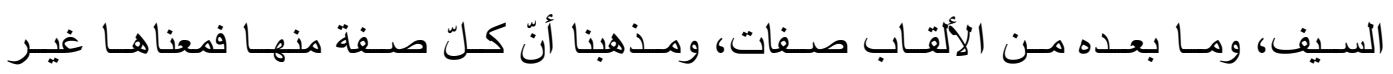

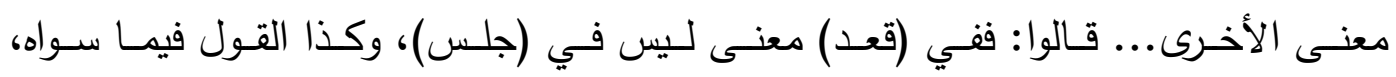

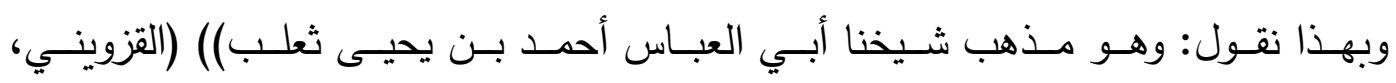

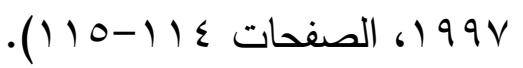

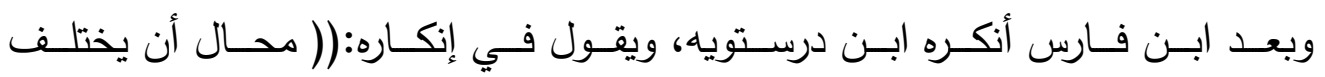

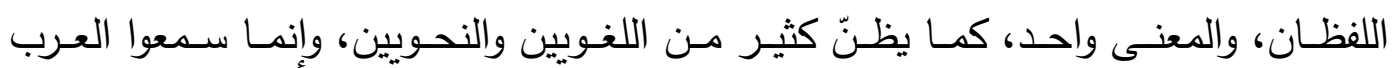

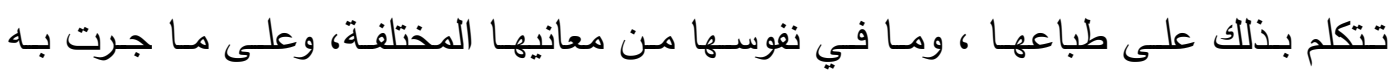

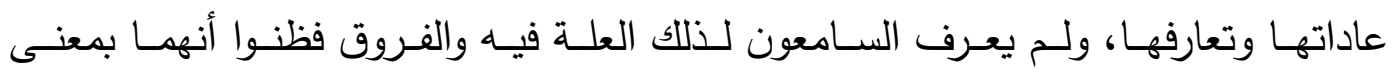

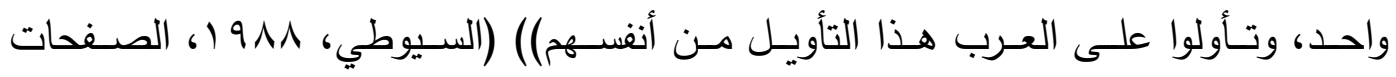

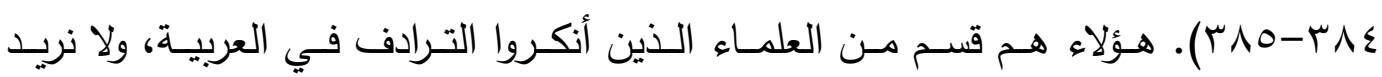

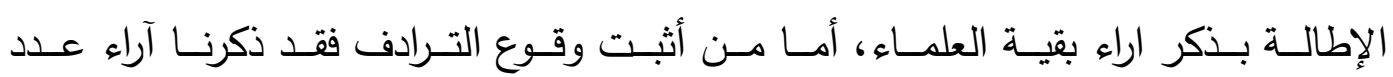

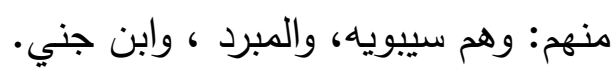

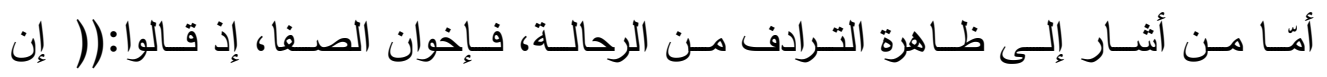
الأقاويـل تختلف تـارة مـن جهـة اللفظ، وتـارة مـن جهـة المعنىى، وتـارة منهمـا جميعًا....

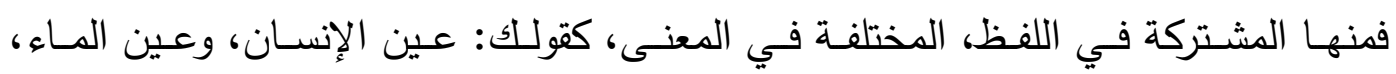

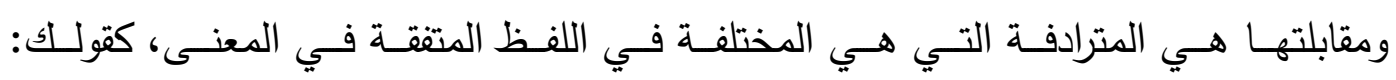

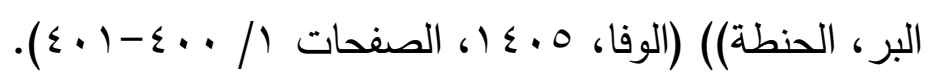

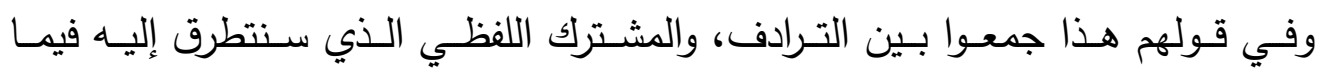

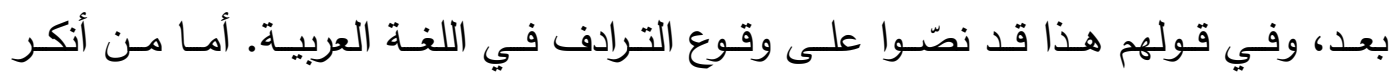

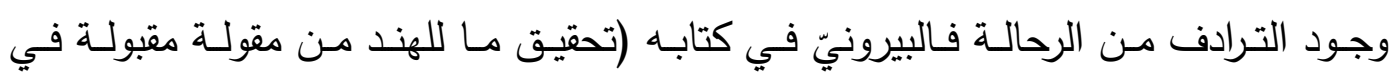

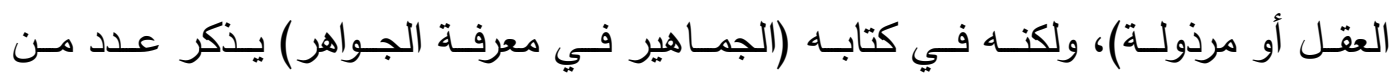

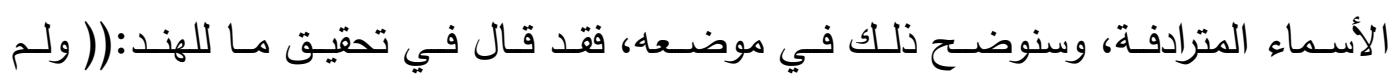

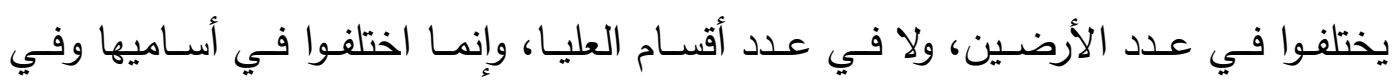


ترتيـب الأسـاميّ، فربّهـا أحمـل ذلـك الاخـتلاف على سـعة اللغـة فـإنهم يسـمّون الثـيء الواحـد بأسـماء كثيـرة جـدًا، والمثـال بالثـمس فـإنهم سـمّوها بـألف اســم على مـا ذكـروا، كتسـمية العـرب الأســـ بقريـب مـن ذلـك بعضـها مقتضـبة، وبعضـها مشـتقة مـن الأحسوال

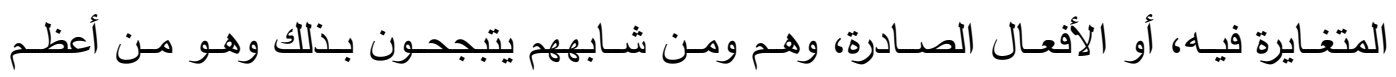

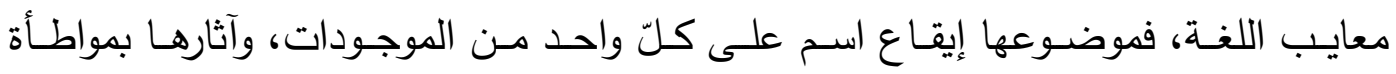
بـين نفر يُعـرَف بهـا بعضـهم عـن بعض غرضـهـ عند إظهار ذلك الاســ بـالنطق، فـإذا

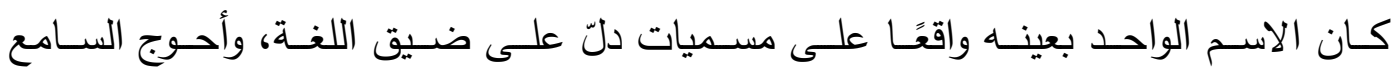

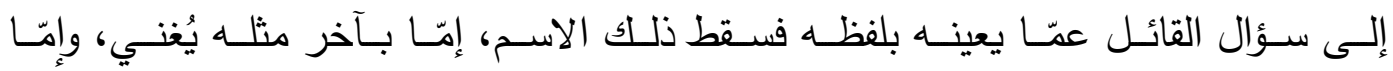
بتفسير معرّف للمعنى)) (البيروني، 901 (، الصفحات 01 1 - 71 ( ). المبحث الثاني: سندرس الأسماء المترادفة التي وردت عند الرحال على قسمين: القســم الأوّل: قـد وقف الرحالـة عند عـد مـن الألفـاظ المترادفـة التي تـدل على معنى واحد عندهم، ومن هؤلاء الرحالة:

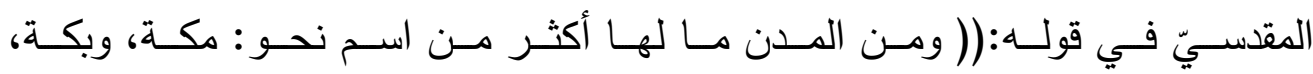
المدينة، يثرب، طيبة، طابة)) (المقدسي، (99 (، صفحة ، ـب).

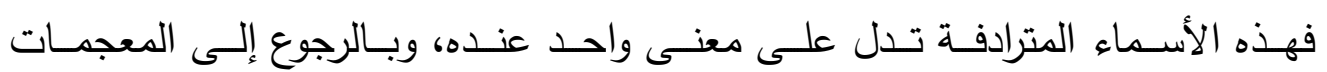

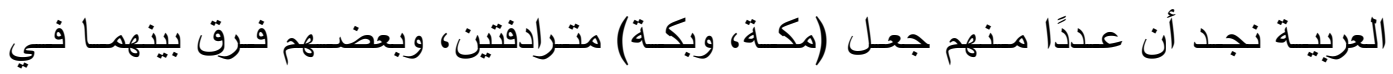

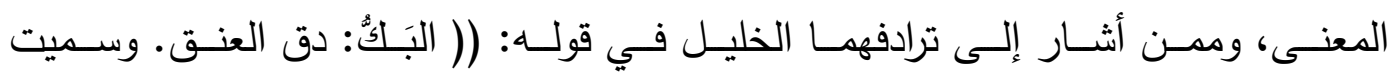

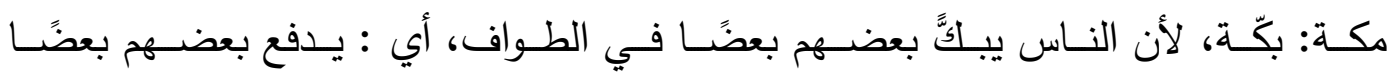

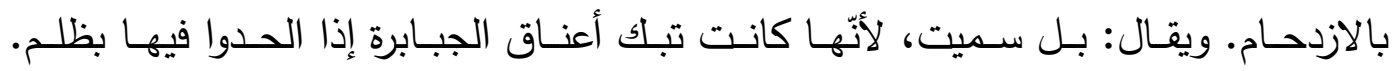

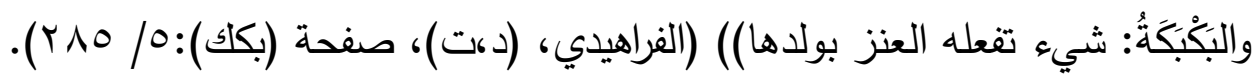

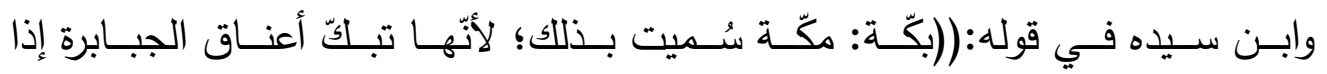

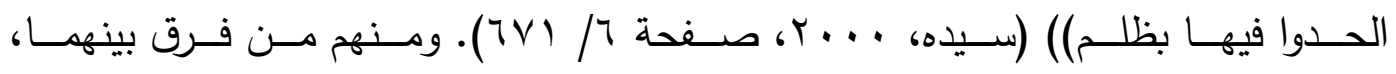

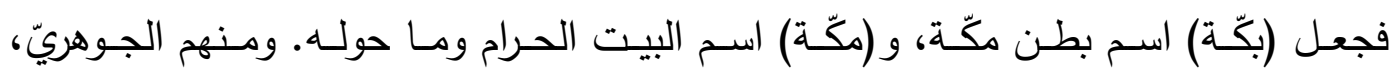

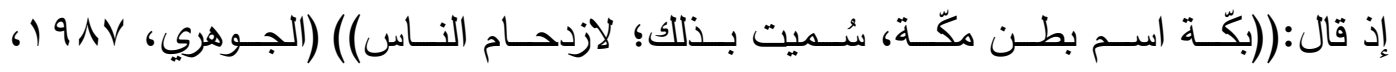

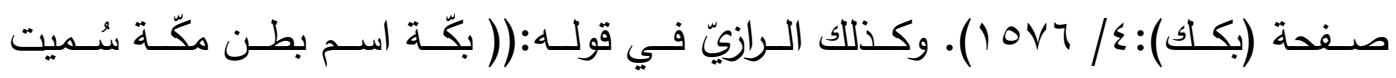

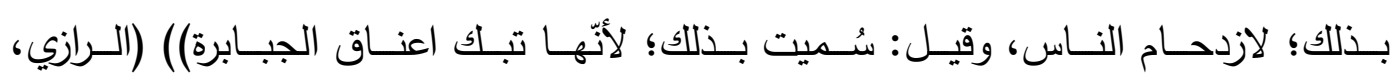

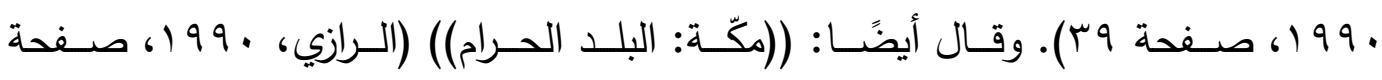

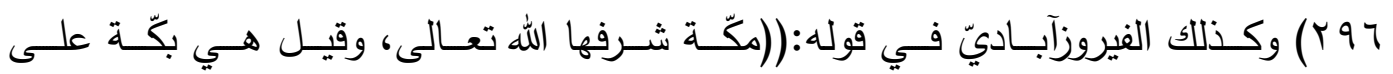

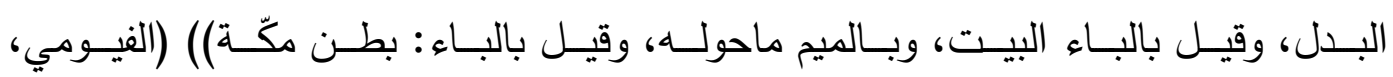

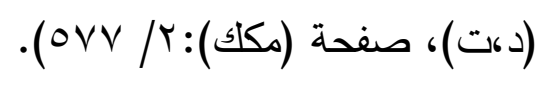




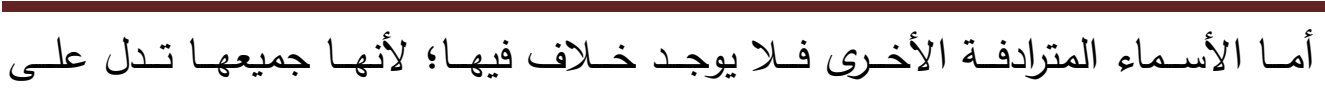

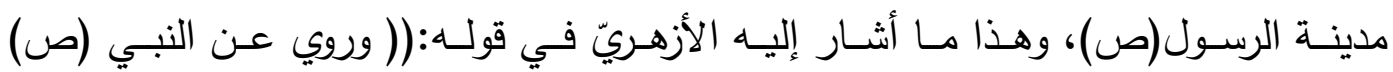

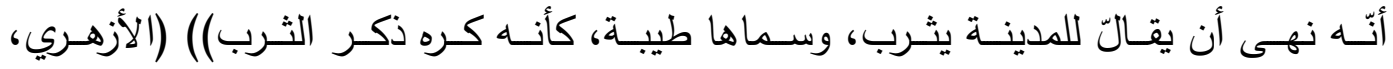

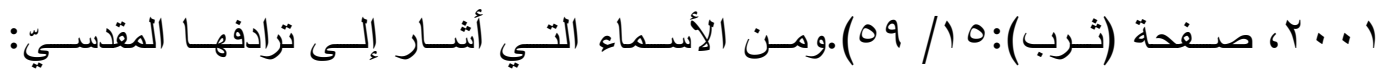

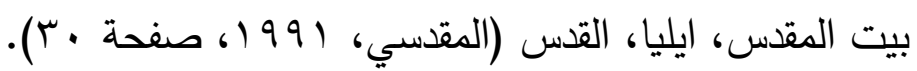

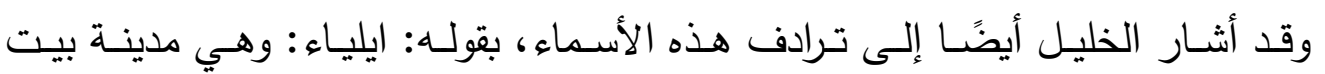

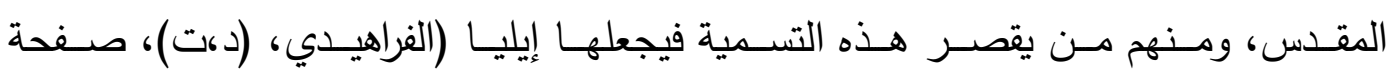
( rov /A:) (أيل)

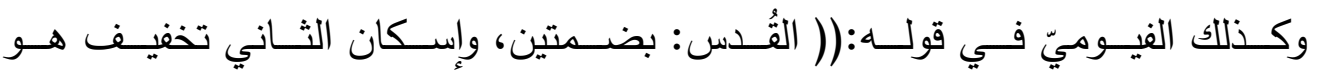

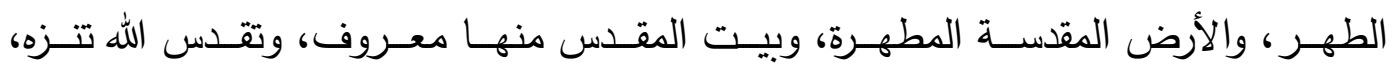

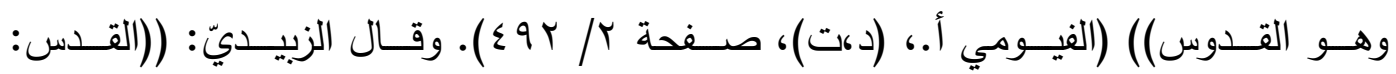

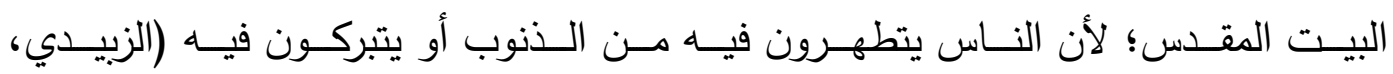

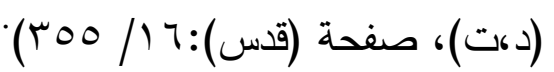

فهذه الاسماء جميعها تدل على مكان واحد، عند المقدسيّ، وعند المجميين.

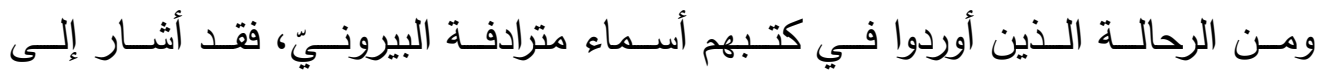

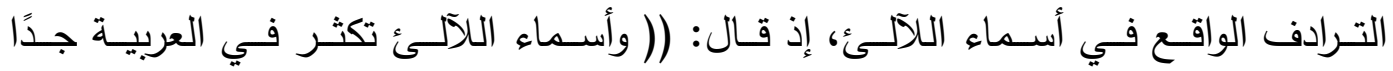

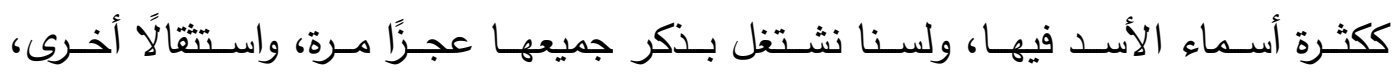

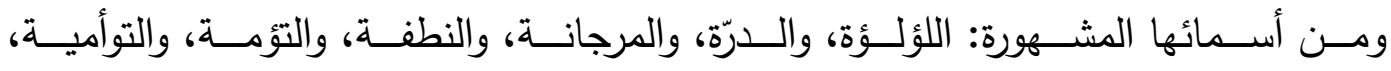

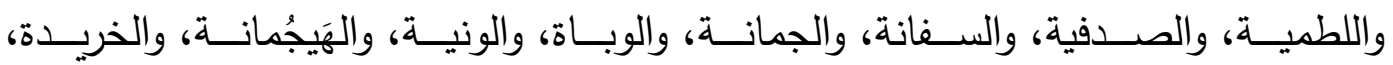

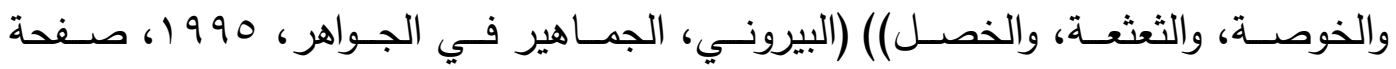

فقولـه هـذا يـلـل على أن هـذه الأسـماء جميعًا تطلق على اللؤلـؤ بصـورة عامــة

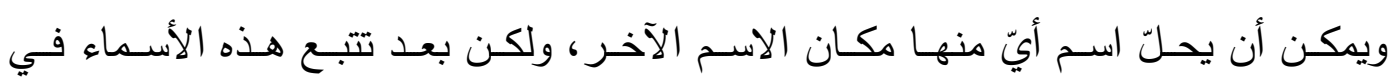

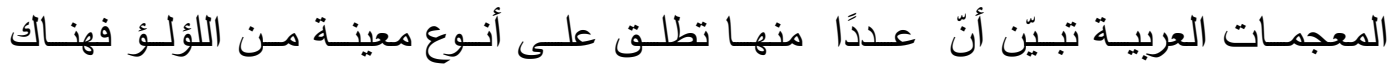
فروق فيها.

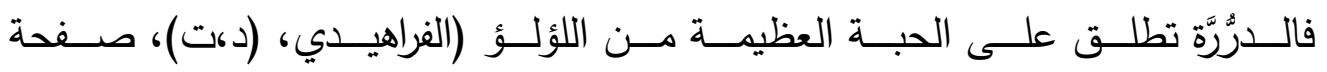

$$
\text { . ( } \vee \wedge:(د)
$$

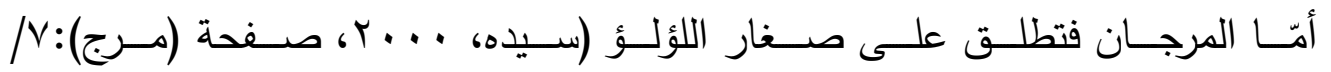




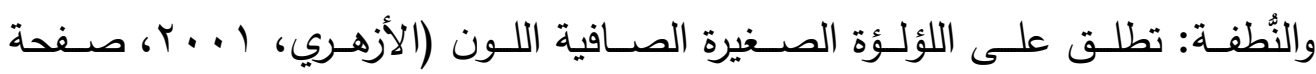

$$
\text { . }
$$

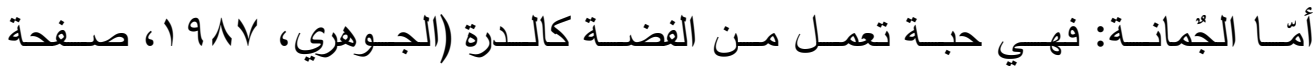

$$
\text { (جمن)(ب) }
$$

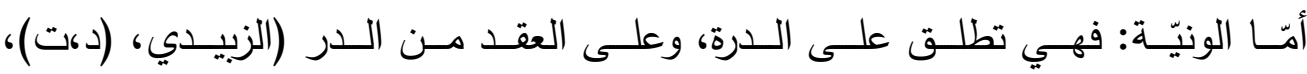

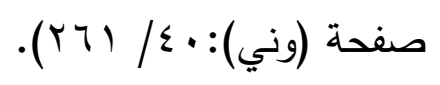

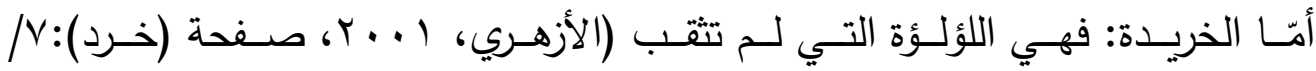

فهذه الأسـماء لايمكن القول بترادفها وإن كانت جميعها تنتمس إلى جنس اللؤلـؤ؛

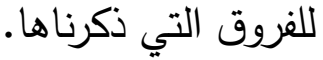

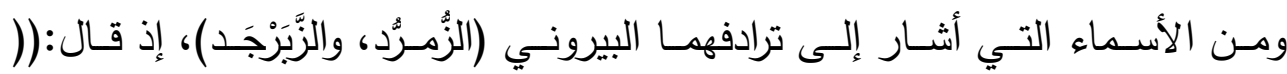

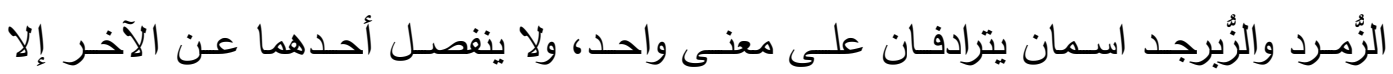

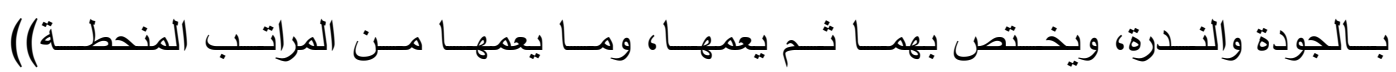

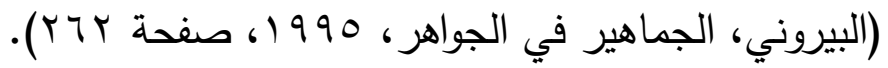

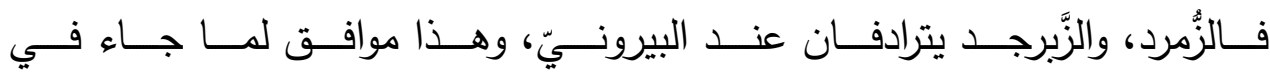

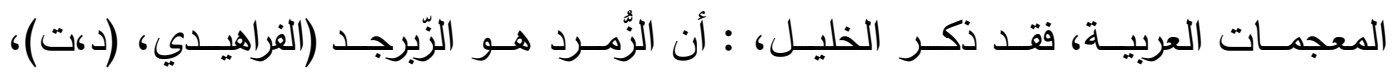

$$
\text { صفحة (زبرجد):T/ • (Y) }
$$

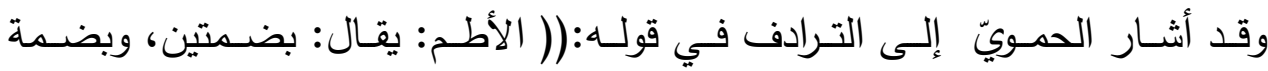

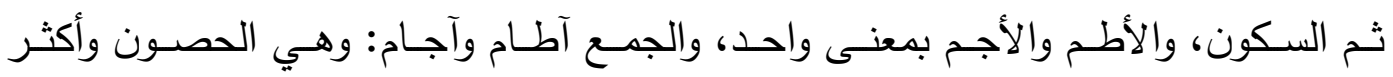

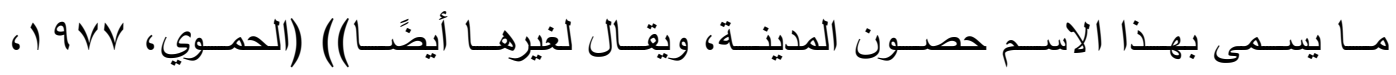

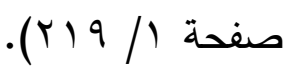

فـالأطم والأجم: تترادفـان على معنى واحـد، وهـو الحصـون، وهـذا موافق أيضًا

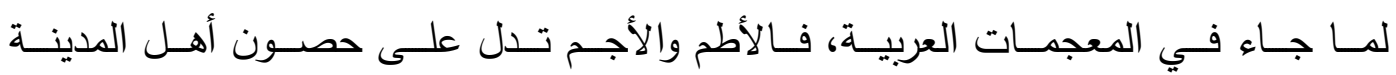

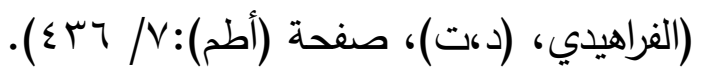

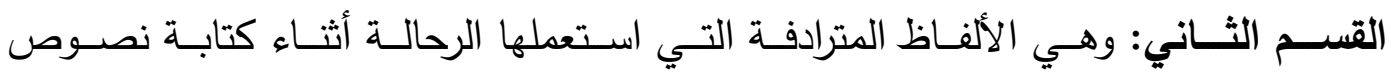
رحلتهم، ومن هذه الألفاظ التي نشير إليها على سبيل التمثيل لا الحصر :

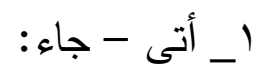

استعمل عدد من الرحالة هاتين اللفظين المترادفتين أثناء كتابة نص الرحلة، ومنهم:

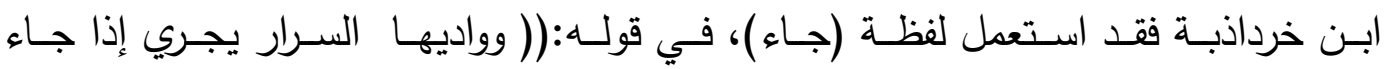

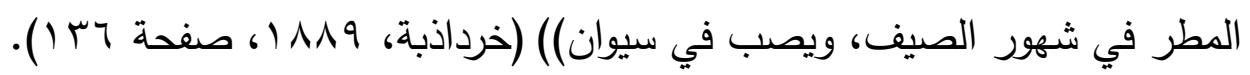




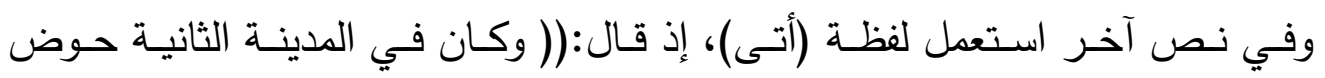

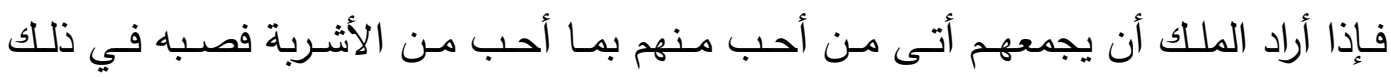

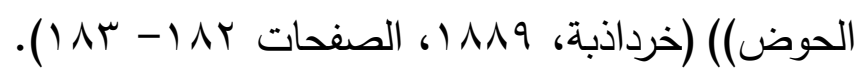

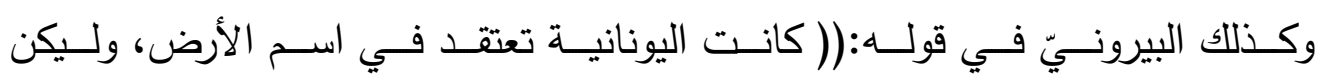

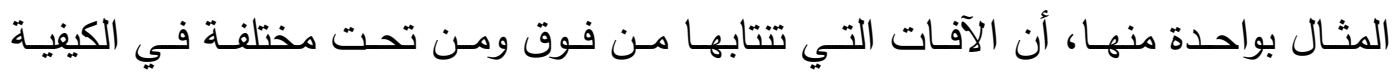

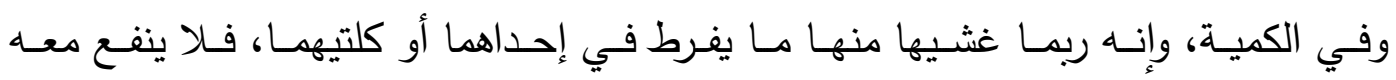

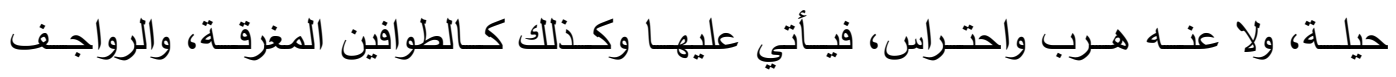

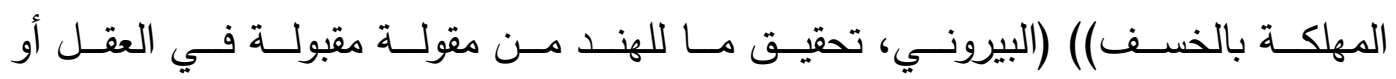

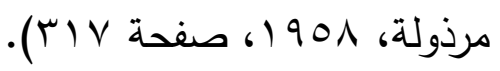
واسـتعمل لفظــة (جـاء)، فـي قولـه:(( ثـم استصـفى المـــوك بعـده فـارس والعـراق

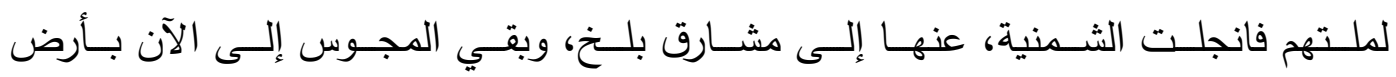

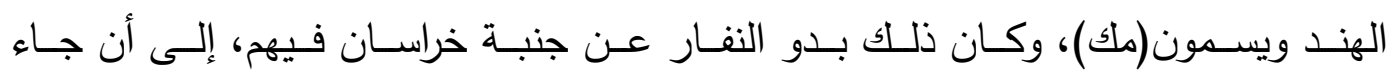

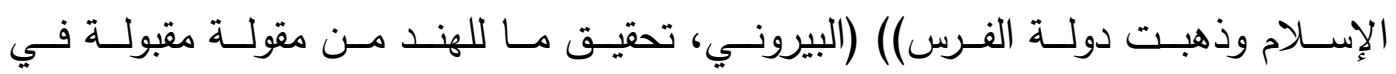

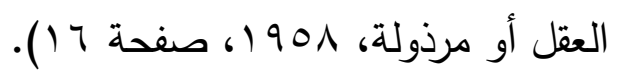

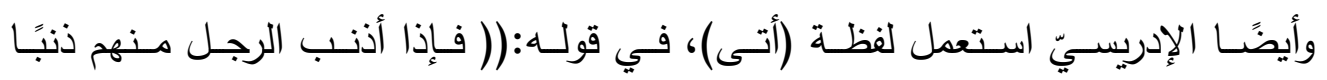

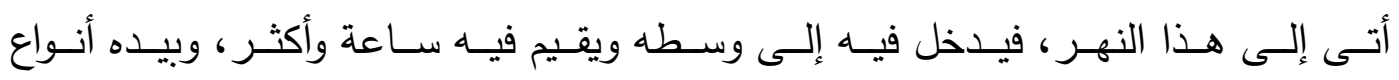

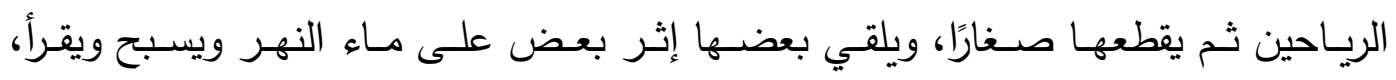

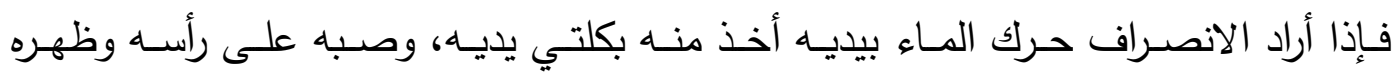

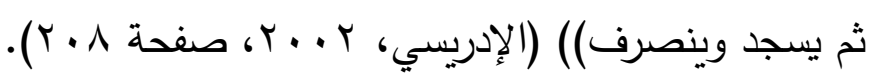

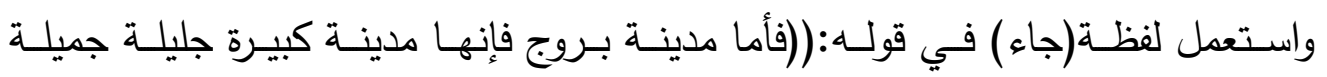

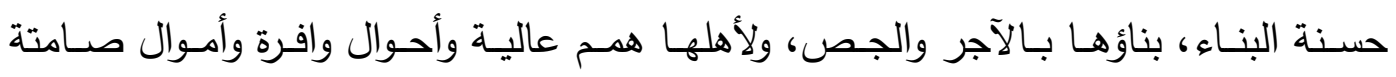

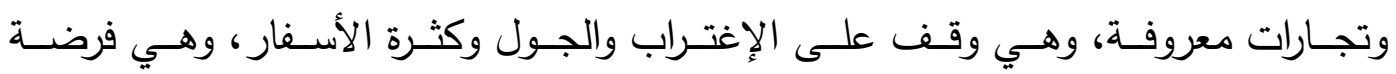

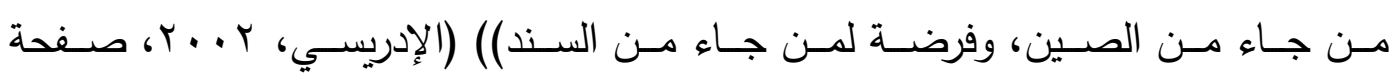
.$(1) \mathrm{V}$ وكذلك ابـن جبيـر اسـتعمل لفظـة (أتسى) في قولـه:(( وأقىنـا ليلتــا تلك في هـول

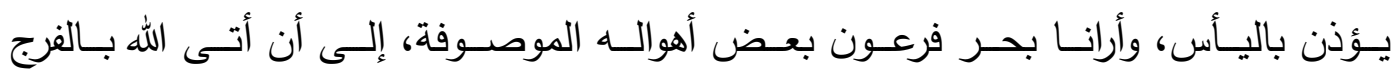

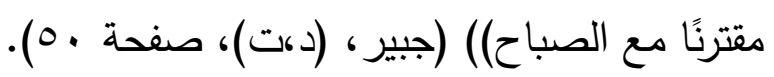

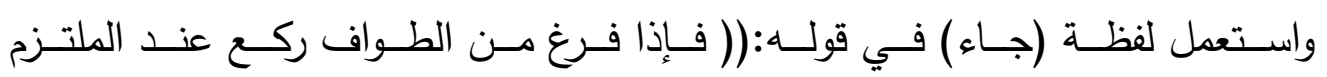

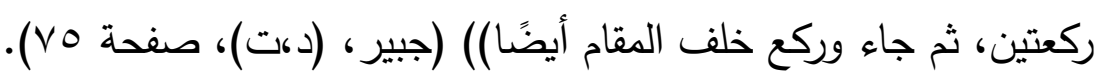




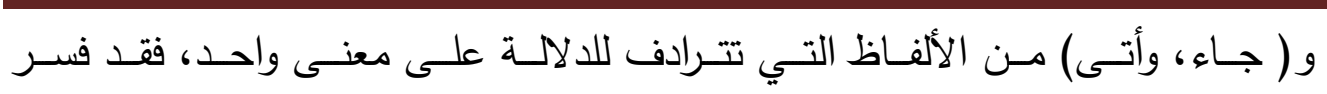

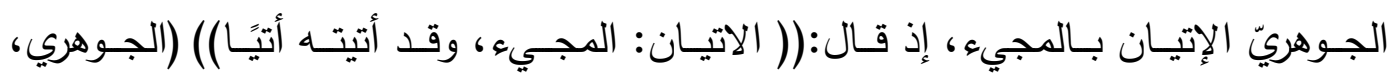

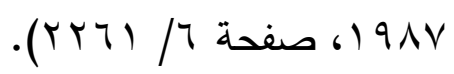

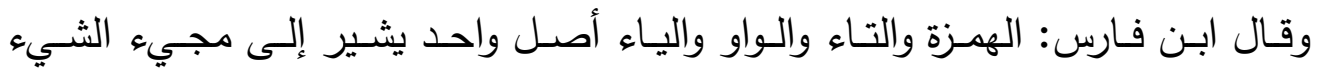

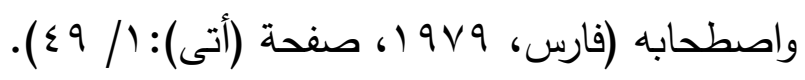

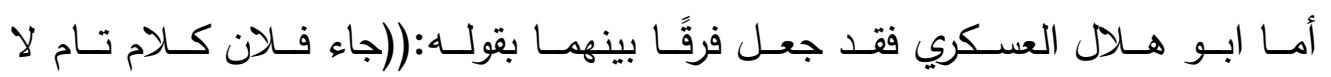

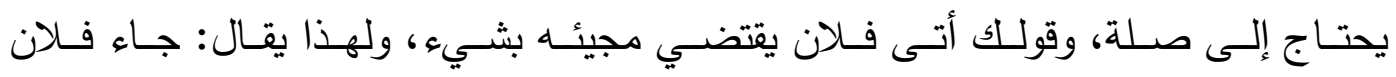

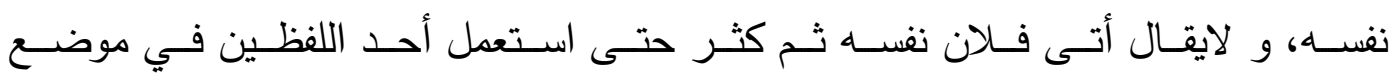

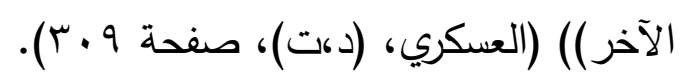

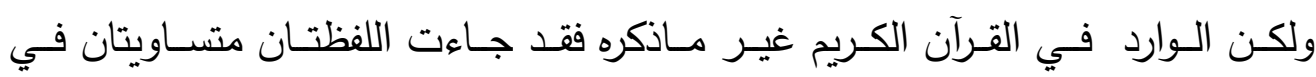

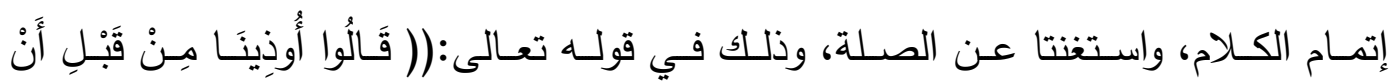

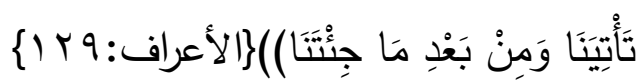

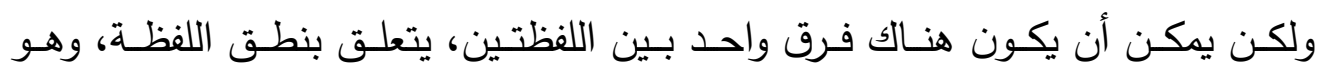

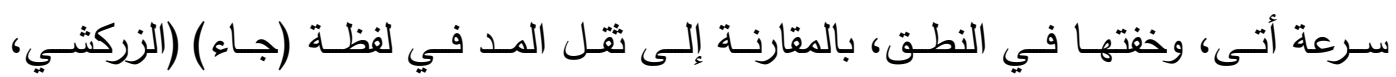

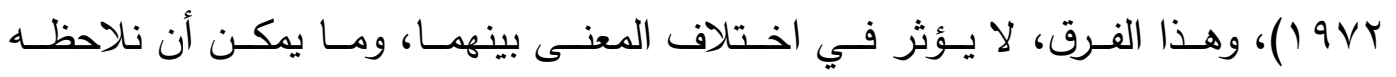

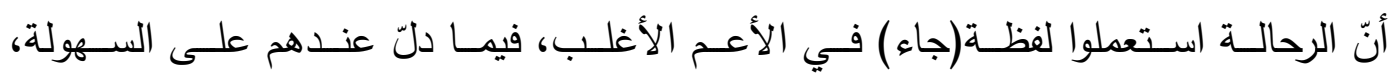

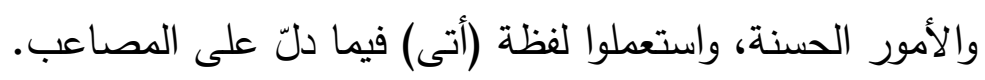

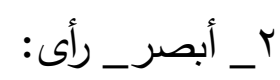
استعمل عدد من الرحالة هاتين اللفظتين في نصوص مختلفة من رحلتهم، ومنهم:

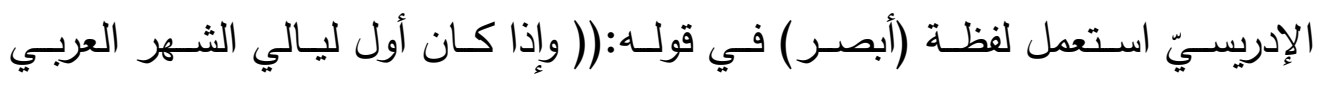

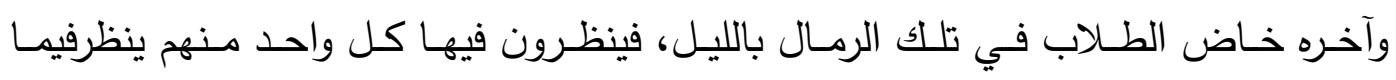

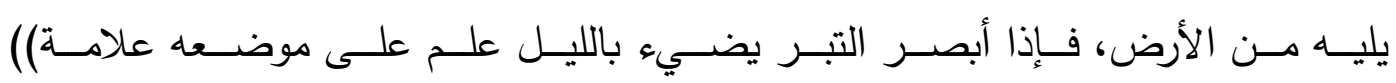

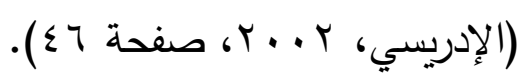

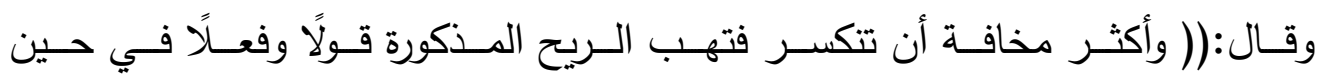

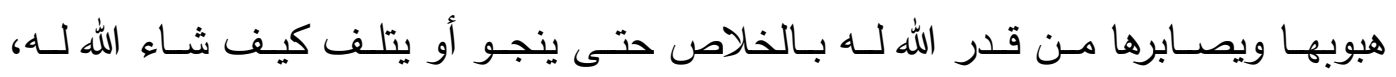

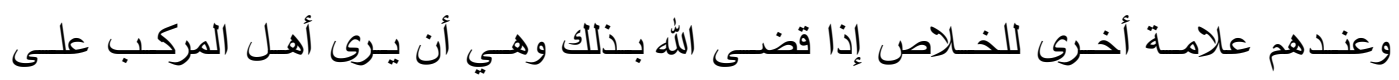

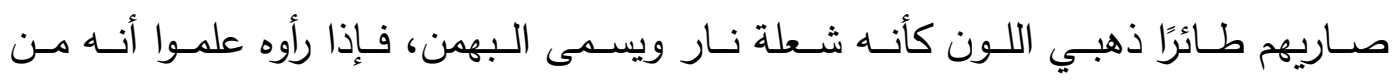

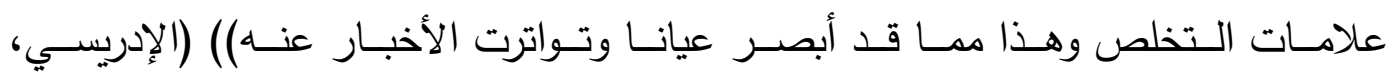

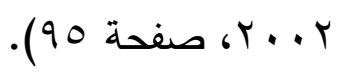


وأيضًا ابـن جبيـر اسـتعمل لفظــة (أبصـر ) فـي قولـه:((فأخبرني مـن أبصـر كثيـرًا

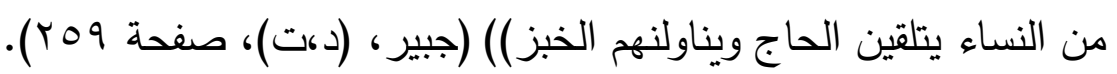

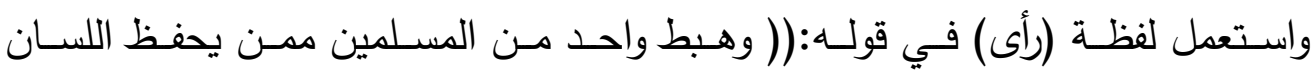

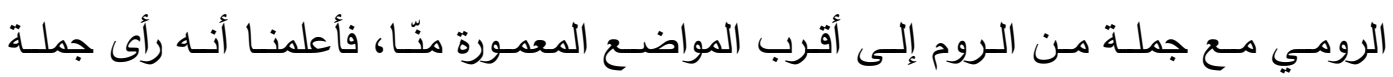

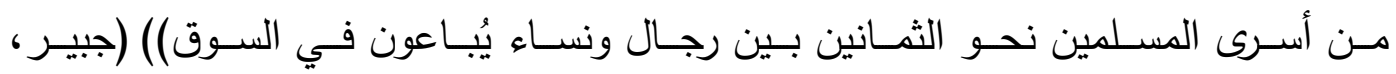

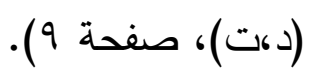

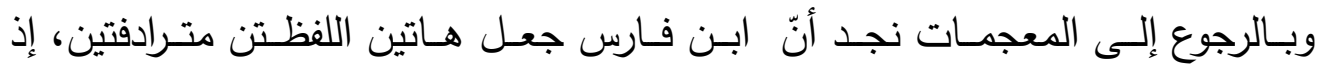

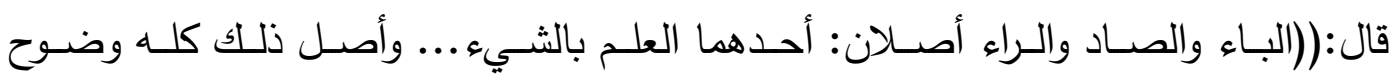

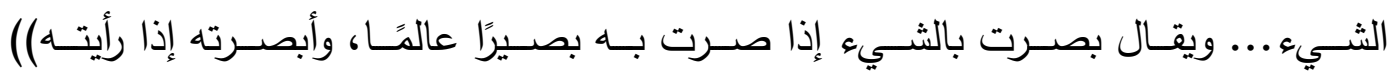

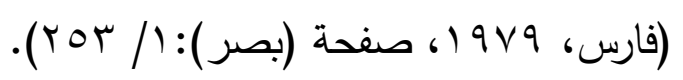

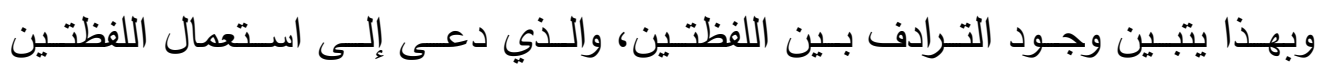

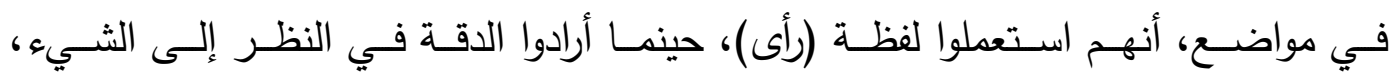

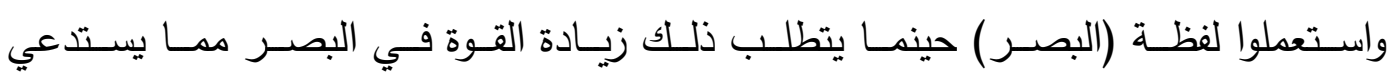

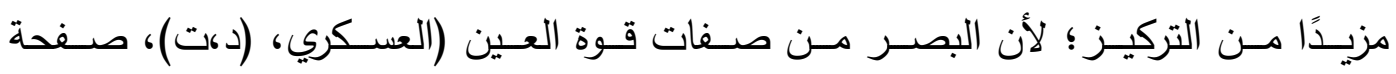

$$
\text { r باء_ - بعيد }
$$

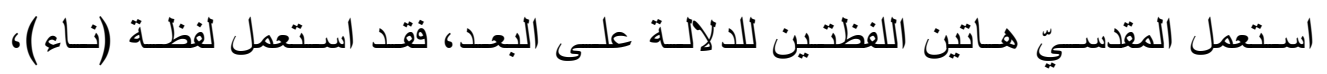

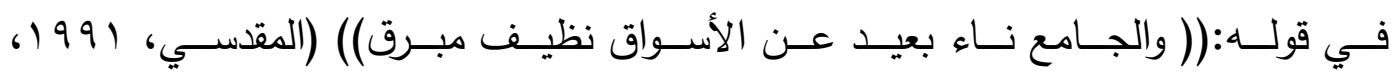
صفحة ع ( ).

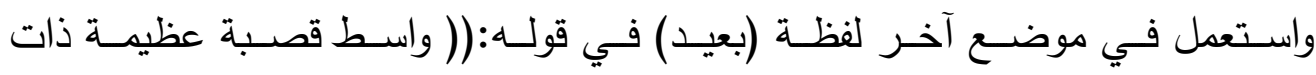

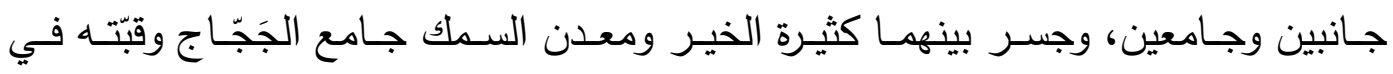

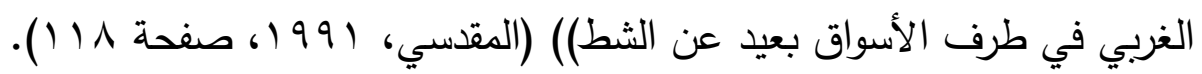

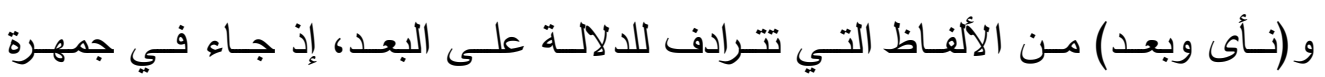

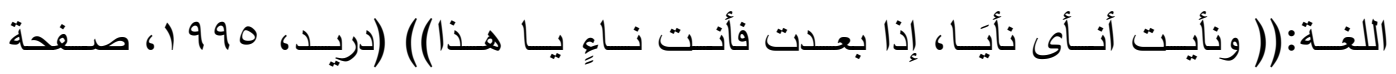

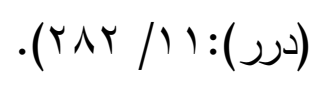

ع- السنة- العام- الحول: وردت هذه الألفاظ عند عدد من الرحالة، ومنهم:

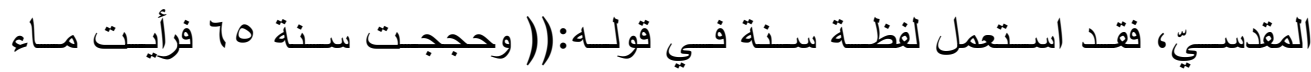

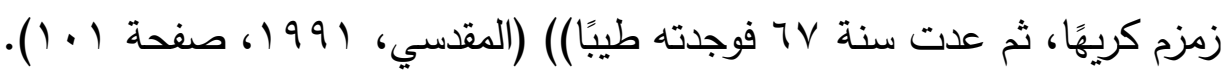

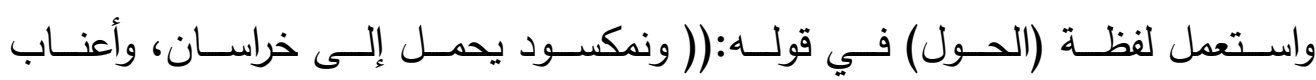

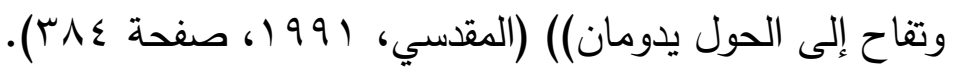


وكذللك البكري استعمل لفظـة (سـنة) في قولـه:(( ولمـا أغـارت الحبشــة زمـن عمـر

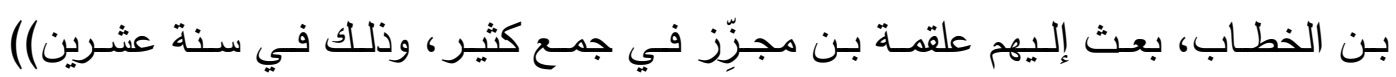

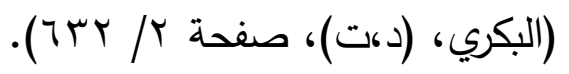

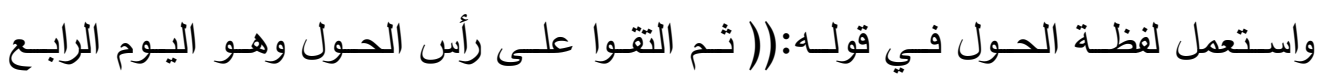

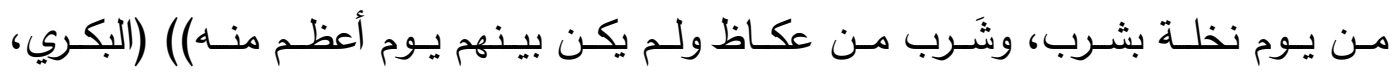

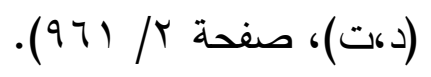

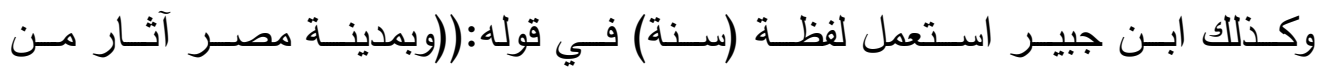

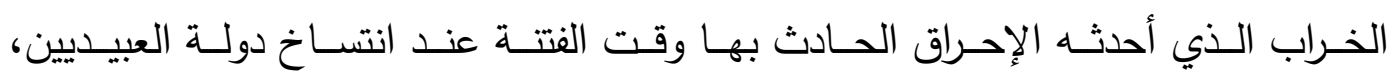
وذللك سنة أربع وستين وخمس مئة)) (جبير، (د،تان)، صفحة و ب).

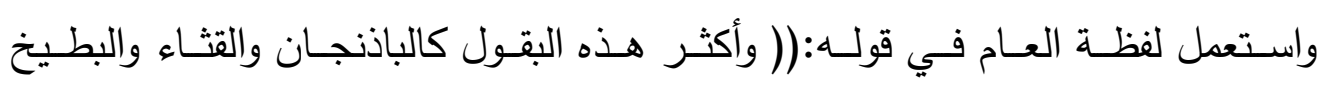

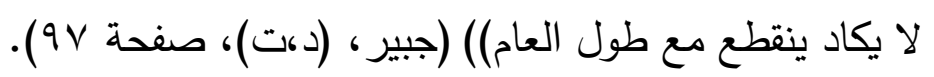

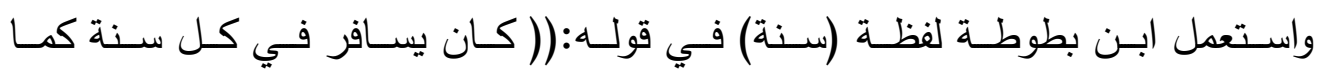

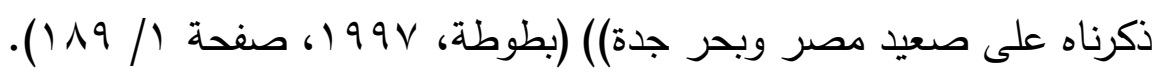

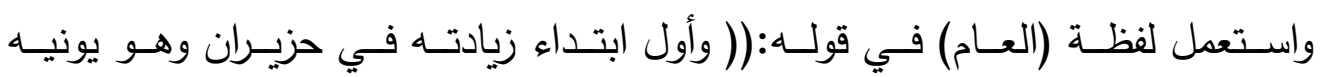

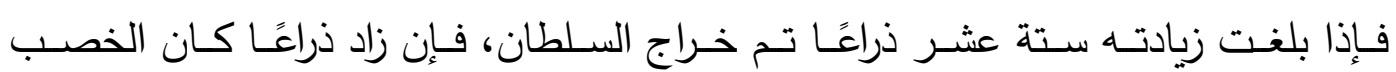

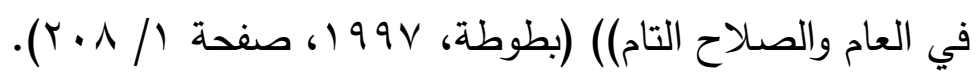

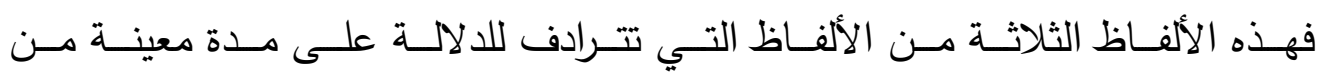

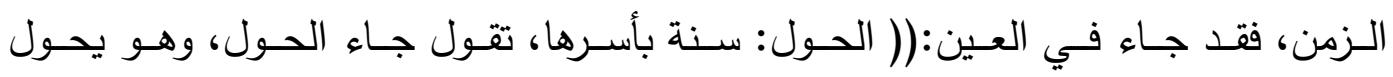

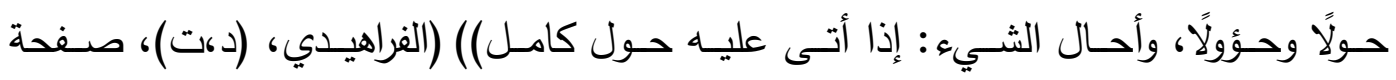

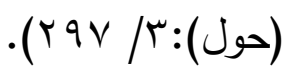

وقد أثـار ابـن فـارس أن الحـول هـو العـام في قولـه:(( الحـاء والـواو والـلام: أصـل

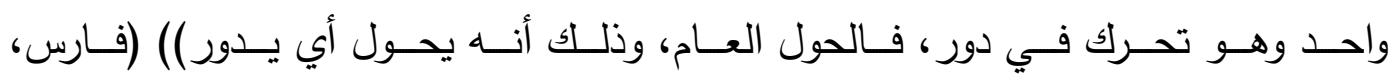

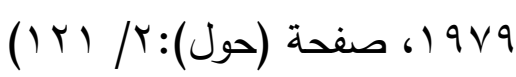

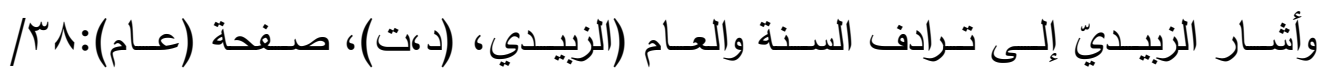

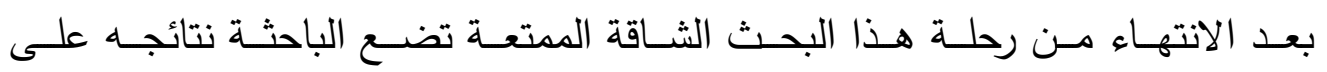

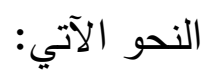

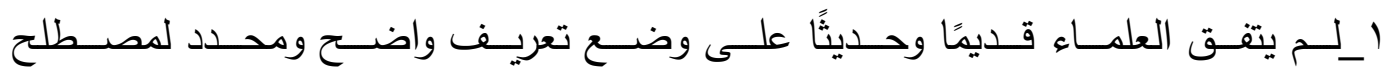




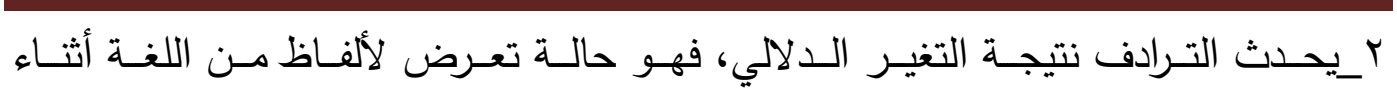
حياتها نتيجة التغير الدلالي بفعل الاستعمال. r_ تتبه الرحالة إلى وجود عدد من الألفاظ المترادفة لذلك ذكروها في كتبهم.

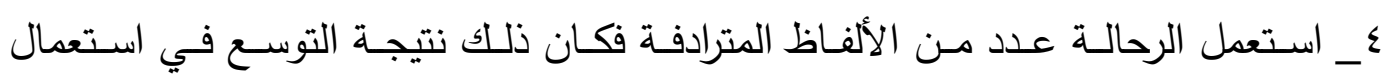

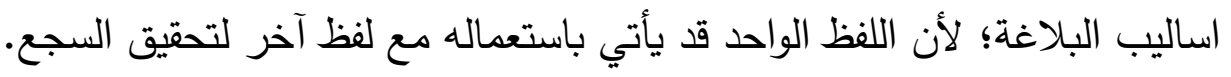

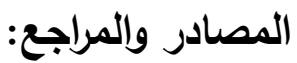
أبو الحسن أحمد بن فارس. (9V9) (199). مقاييس اللغة. دار الفكر.

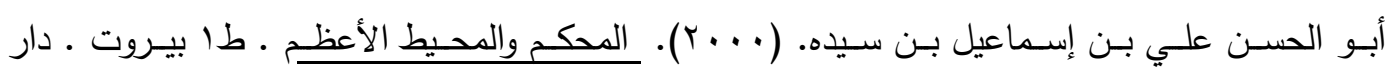

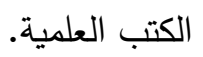

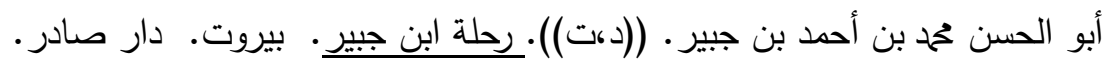

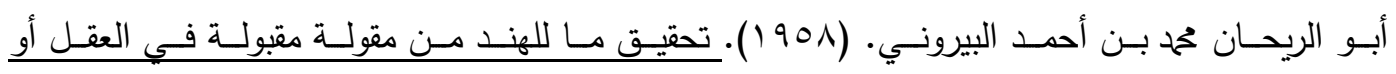
مرذولة. الهند. مطبعة دار المعارف العثمانية.

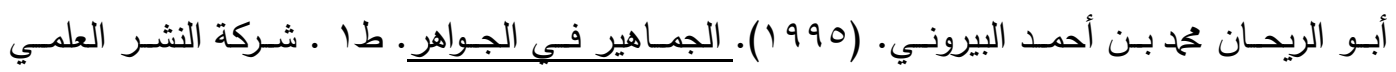
والثقافي.

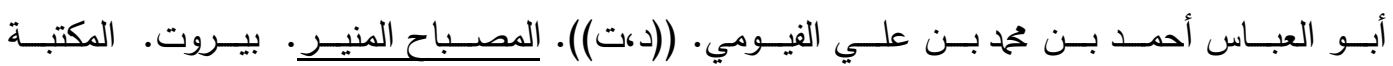
العلمية. أبو الفتح عثمان بن جني. ((د،ت)). الخصائص. بيروت. عالم الكتب.

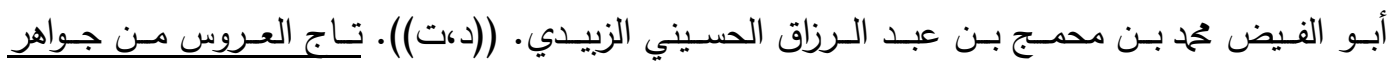
القاموس. دار الهداية.

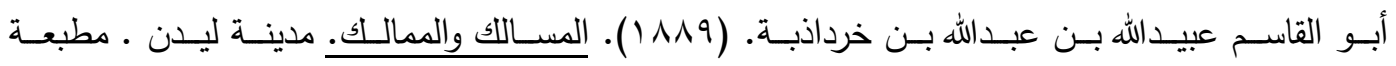

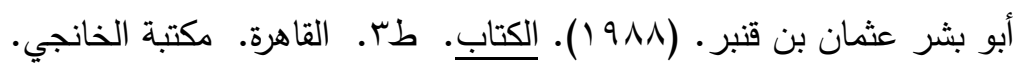

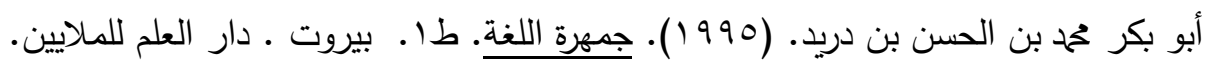

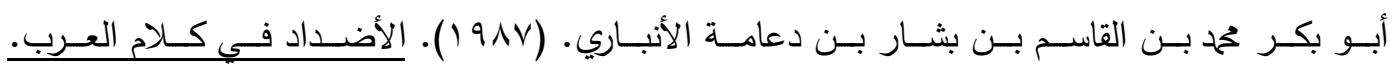
بيروت- لبنان. الككتبة العصرية.

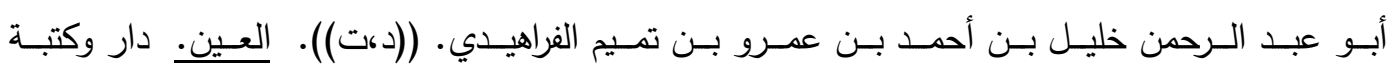

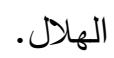

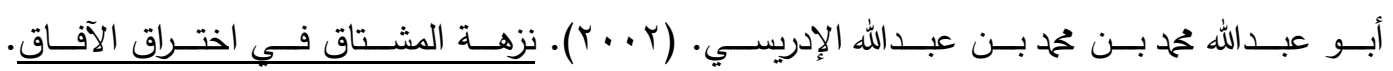
القاهرة. مكتبة الثقافة الدينية.

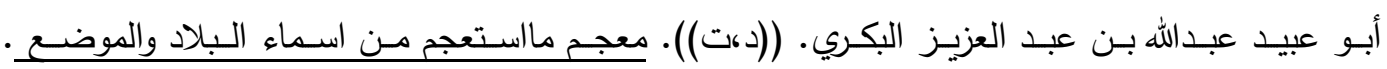
بيروت ـ عالم الكتب.

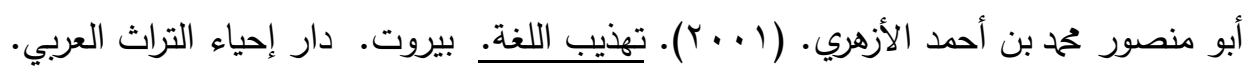

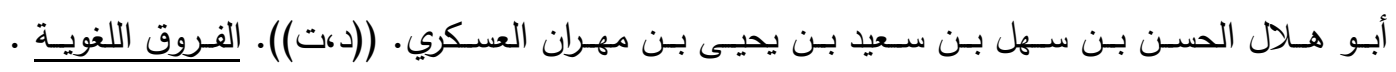
القاهرة. دار العلم والثقافة للنشر والتوزيع. 


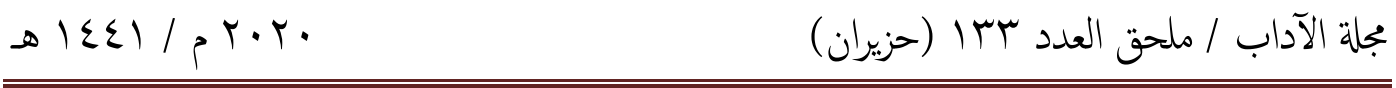

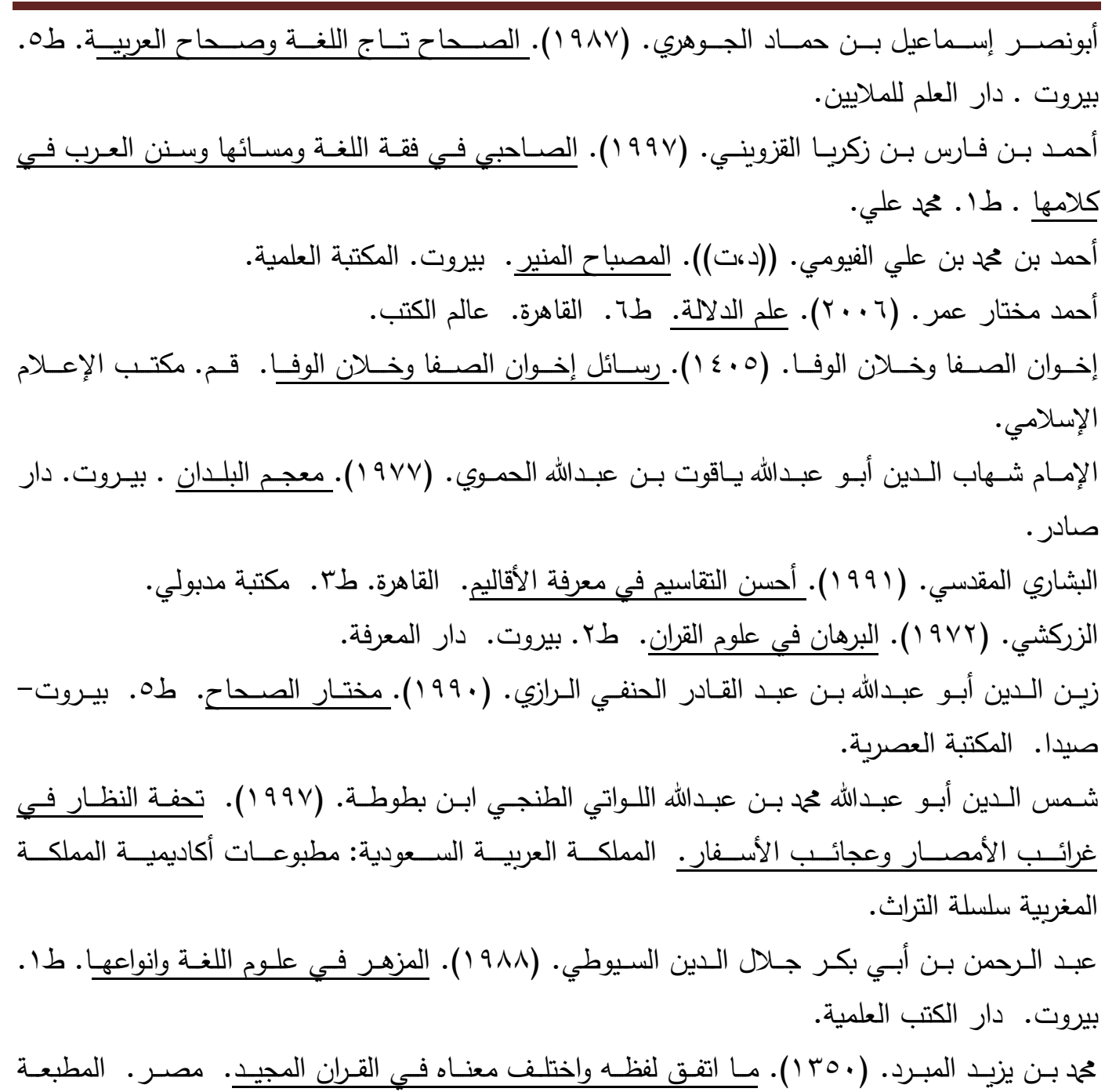
السلفية.

\section{Resources and References:}

Abu Al-Hasan Ahmed Bin Faris (1979). Maqyees Al-Lugha. Dar Al-Fikir

Abu Al-Hasan Ali Bin Ismael Bin Seida (2000). Al-Muhkam wa AlMuheet Al-Adham . $1^{\text {st }}$ edition. Beirut. Dar Al-Kotob Al-Ilmiya.

Abu Al-Hasan Mohammed Bin Ahmed Bin Jubeir. (n.d) Rihlat Bin Jubeir. Beirut. Dar Sadir.

Abu Al-Rihan Mohammed Bin Ahmed Al-Bayroni. (1958). Tahqeek ma Lalhind min Maqula Maqbola fi Al-Aqil ao Marthola. India. Dar AlMaarif Al-Authmaniya

Abu Al-Rihan Mohammed Bin Ahmed Al-Bayroni. (1995). Al-Jamheer fi Al-Jawahir. ${ }^{\text {st }}$ Edition. Scientific and Cultural Publishing Company.

Abu Al-Abbas Ahmed Bin Mohammed Bin Ali Al-Fayomi. (n.d). AlMusbah Al-Muneer.

Beirut.

Al-Maktaba Al-Ilmiya

Abu Al-Fatah Authman Bin Jini. (n.d). Al-Khasais. Beirut. Alam AlKotob.

Abu Al-Feidh Mohammed Bin Mohammed Bin Abdulrazaq Al-Huseini Al-Zubeidi. (n.d). Taj Al-Aroos min Jwahir Al-Qamoos. Dar Al-Hidaiya. 
Abu Al-Qasim Aubeidallah Bin Khardathaba. (1889) Al-Masalik wa AlMamalik. Leiden. Brille Press.

Abu Bashar Authman Bin Qanbar. (1988). Al-Kitab. $3^{\text {rd }}$ Edition. Cairo. Maktabat Al-Khanji

Abu Bakar Mohammed Bin Al-Hasan Bin Dureid. (1995) Jamahrat AlLugha. ${ }^{\text {st }}$ Edition. Beirut. Dar Al-Ilim Lalmalaeen.

Abu Bakar Mohammed Bin Al-Qasam Bin Bashar Bin Da'ama AlAnbari. (1987). Al-Athdad fi Kalam Al-Arab. Beirut. Lebonon. AlMaktaba Al-Asriya.

Abu Abdulrahaman Khaleel Bin Ahmed Bin Amro Bin Tameem AlFaraheedi. (n.d). Al-Aen. Dar wa Maktabat Al- Hilal.

Abu Abduallah Mohammed Bin Mohammed Bin Abdullah Al-Idreesi. (2002) Nuzhat Al-Mushtaq fi Ikhtraq Al-Afaaq. Cairo. Maktabat AlThaqafa Al-Deeniya.

Abo Aubeid Abdullah Bin Abdulazeez Al-Bakri. (n.d). Mu'jam Ma Ista'jam Min Asmaa Al-Bilad wa Almawthi'. Beirut. Elam Al-Kutub.

Abu Mansoor Mohammed Bin Ahmed Al-Azhari. (2001). Tahtheeb AlLugha. Beirut. Dar Ihea' Al-Turath Al-Arabi.

Abo Al-Hilal Al-Hasan Bin Sahel Bin Yahiya Bin Muhran Al-Askari. (n.d). Al-Frooq Al-Lighawiya. Cairo. Dar Al-Elim wa Althakafa for Publication wa Distribution.

Abo Nasir Ismaeel Bin Humad Al-Jawhari. (1987). Al-Sihah Taj AlLugha wa Sihah Al-Arabia. $5^{\text {th }}$ Edition. Beirut. Dar Al-Elim Lel-Malaeen.

Ahmed Bin Faris Bin Zakariya Al-Qizweeni. (1997). Al-Sahibi fi Fiqih Al-Lugha wa Masauha wa Sunan Al-Arab fi Kalamaha. $1^{\text {st }}$ Edition. Mohammed Ali.

Ahmed Bin Mohammed Bin Ali Al-Fayumi. (n.d). Al-Musbah AlMuneer. Beirut. AlMaktaba Al-Elmiya.

Ahmed Mukhtar Omar. (2006). Eilm Al-Dalala. $6^{\text {th }}$ Edition. Cairo. Alim Al-Kutub.

Ikhwan Al-Safa wa Khilan Al-Wafa. (1405). Rasaeil Al-Safa wa Khilan Al-Wafa. Qom. Al-Eilam Al-Islami Office.

Iman Shihab Al-deen Abo Abdullah Yaqoot Bin Abidullah Al-Hamwi. (1977). Mu'jam Al-Buldan. Beirut. Dar Sadir

Al-Bashari Al-Muqadisi. (1991). Ahsan Al-Taqaseem fi Ma'rifat AlIqleem. Cairo. $3^{\text {rd }}$ Edition.. Maktabat Madboli.

Al-Zarkashi. (1972). Aburhan fi Ulom Al-Qur'an. $2^{\text {nd }}$ Edition. Beirut. Dar Al-Ma'rifa.

Zeinuldeen Abo Abdullah Bin Abdulqadir Al-Hanafi Al-Razi. (1990). Mukhtar Al-Sihah. $5^{\text {th }}$ Edition. Beirut- Saida. Al-Maktaba Al-Asriya.

Shamsuldeen Abo Abdullah Al-lawati Al-Tanji Bin Batota. (1997). Tuhfat Al-Andhar fi $\quad$ Ghara'ib Al-Amsar wa Aja'ib Al-Asfar. Saudi Arabia. Publications of the Academy of the Kingdom of Morocco-Heritage Series.

Abdulrahaman Bin Abi Bakir Jalaluldeen Al-Siyoti. (1988). Al-Muzhir fi Elom Al-Lugha wa Anwa'aha. $1^{\text {st }}$ Edition. Beirut. Dar Al-Kutub AlIlmiyah.

Mohammed Bin Yazeed Al-Mubrid. (1350). Ma Itafaq Lafdhaho wa Ikhtalaf Ma'nah fi Al-Quran. Cairo. Al-Sulfiya press. 


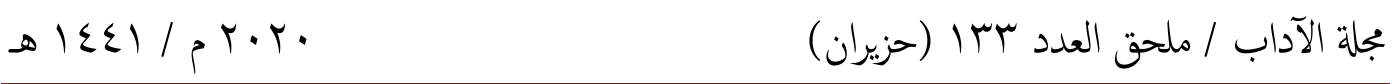

\title{
Tandem when traveling Until the end of the eighth century AH
}

\author{
Basma Abdullah Fade \\ Prof. Dr. Hassan Jaafar Sadiq
}

\begin{abstract}
:
Tandem is manifestation of the arabic language, an important characteristic of its characteristics, and is one of the means of language that helps to grow the language and increase its linguistic wealth, it is one of the means that enriched the Arabic dictionaries in many words until the Arabic dictionaries can express the same meaning in more than one word of Without ambiguity in meaning, and by tword, we can know the words that are shared with each other semantically, as well as the contexts in which the words of the same connotation change, and the books of travellers have been characterized by the existence of a number of synonyms, because they have studied the languages of the countries and territories they visited, Some of them have stated it, and some have not stated it, so this research deals with the definition of "tandem", and the statement of the opinions of the scholars and their differences around them, and sought to extrapolate the synonyms in the books of travellers, and described and balanced them with what the linjuists said
\end{abstract}

